\title{
The role of the cerebellum in motor cognition.
}

Citation for published version (APA):

van Mier, H. I., \& Petersen, S. E. (2002). The role of the cerebellum in motor cognition. Annals of the New York Academy of Sciences, 978, 334-353. https://doi.org/10.1111/j.1749-6632.2002.tb07578.x

Document status and date:

Published: 01/01/2002

DOI:

10.1111/j.1749-6632.2002.tb07578.x

Document Version:

Publisher's PDF, also known as Version of record

\section{Document license:}

Taverne

\section{Please check the document version of this publication:}

- A submitted manuscript is the version of the article upon submission and before peer-review. There can be important differences between the submitted version and the official published version of record.

People interested in the research are advised to contact the author for the final version of the publication, or visit the DOI to the publisher's website.

- The final author version and the galley proof are versions of the publication after peer review.

- The final published version features the final layout of the paper including the volume, issue and page numbers.

Link to publication

\footnotetext{
General rights rights.

- You may freely distribute the URL identifying the publication in the public portal. please follow below link for the End User Agreement:

www.umlib.nl/taverne-license

Take down policy

If you believe that this document breaches copyright please contact us at:

repository@maastrichtuniversity.nl

providing details and we will investigate your claim.
}

Copyright and moral rights for the publications made accessible in the public portal are retained by the authors and/or other copyright owners and it is a condition of accessing publications that users recognise and abide by the legal requirements associated with these

- Users may download and print one copy of any publication from the public portal for the purpose of private study or research.

- You may not further distribute the material or use it for any profit-making activity or commercial gain

If the publication is distributed under the terms of Article $25 \mathrm{fa}$ of the Dutch Copyright Act, indicated by the "Taverne" license above, 
PDFlib PLOP: PDF Linearization, Optimization, Protection

Page inserted by evaluation version www.pdflib.com - sales@pdflib.com 


\title{
Role of the Cerebellum in Motor Cognition
}

\author{
HANNEKE I. VAN MIER ${ }^{a}$ AND STEVE E. PETERSEN ${ }^{b}$ \\ ${ }^{a}$ Neurocognition, Faculty of Psychology, University Maastricht, \\ Maastricht, 63110 The Netherlands \\ ${ }^{b}$ Departments of Neurology and Neurological Surgery, Radiology, Anatomy and \\ Neurobiology, Psychology, Washington University School of Medicine, \\ St. Louis, Missouri, USA
}

\begin{abstract}
Cerebellar data from five experiments using different groups of subjects performing the same motor learning task are presented. Positron emission tomography (PET) as well as functional magnetic resonance imaging (fMRI) was used to study changes in cerebellar activations as an effect of learning. Cerebellar brain activations obtained during the performance of a new motor task were compared to activations during the performance of the same task after as well as during practice. To account for changes in velocity and somatosensory processing as an effect of practice, two control conditions were included. Behavioral data showed that as an effect of practice performance speed as well as accuracy increased in all five experiments and groups. Neuroimaging data from adults as well as children showed differential changes in brain activations in different cerebellar areas. In all experiments an area in the left lateral cerebellum showed practice-related decreases, which were most likely related to a decrease in errors. In two experiments a highly significant correlation was found between the decrease in errors and the decrease in left cerebellar activation. An area in the right lateral cerebellum and one in the ipsilateral anterior vermis showed activations that seemed related to the level of capacity at which the subjects were performing and might refer to timing-related aspects of the task.
\end{abstract}

KEYWORDS: motor learning; neuroimaging; PET; fMRI; timing; adults; children

\section{INTRODUCTION}

It is now commonly accepted that the cerebellum is involved in processes beyond that of motor coordination and motor control. Studies involving cerebellar patients have suggested a role for the cerebellum in cognition in both adults ${ }^{1-4}$ and children. ${ }^{5,6}$ Anatomical studies ${ }^{7-9}$ have shown that the cerebellum projects to several prefrontal areas via the thalamus, linking the cerebellum to areas known to be involved in cognitive processes. However, studies using functional neuroimaging techniques have shown beyond doubt that the cerebellum is involved in a wide range of

Address for correspondence: Dr. Hanneke van Mier, Maastricht University, Psychology, Neurocognition, P.O. Box 616, 6200 MD Maastricht, 63110 The Netherlands. Voice: 043-3884010; fax: 043-3884125.

h.vanmier@psychology.unimaas.nl

Ann. N.Y. Acad. Sci. 978: 334-353 (2002). (C) 2002 New York Academy of Sciences. 
cognitive processes. In an impressive overview including 275 neuroimaging studies to explore brain areas involved in cognitive functions, Cabeza and Nyberg ${ }^{10}$ showed that the cerebellum is engaged in a variety of cognitive tasks. Furthermore, findings of cerebellar activation in neuroimaging studies addressing motor imagery ${ }^{11-13}$ and mental navigation ${ }^{14}$ also suggest a role for the cerebellum beyond that of motor control and motor execution.

As for the role of the cerebellum in motor cognition, several hypotheses have been advanced. The cerebellum is thought to be involved in motor learning ${ }^{15-17}$ (for a review of neuroimaging studies showing cerebellar activations in motor learning see van Mier ${ }^{18}$ ), in the coordination of multijoint movements, ${ }^{19-22}$ in the coordination between eye and hand, ${ }^{23}$ in error detection and correction, ${ }^{24}$ as well as in the control of motor timing. ${ }^{25-27}$ Data from anatomical, lesion, electrophysiological, and neuroimaging studies have shown evidence for each hypothesis. However, which theory or combination of theories will be able to describe the apparently diverse role of the cerebellum ${ }^{28}$ is not clear at the moment. Furthermore, it is not unlikely that different parts of the cerebellum might be involved in different aspects of motor control and learning.

The changes in brain activations observed during and after the learning of a sequential motor task are described. In five experiments, five different groups of subjects had to learn a sequence of movement directions by trial and error in order to traverse a maze design as quickly and accurately as possible. Subjects were instructed to move a pen through a cutout design with their eyes closed. Although the whole brain was scanned, this paper focuses only on activations observed in cerebellar areas. Brain activations were measured using two different brain imaging techniques, positron emission tomography (PET) and functional magnetic resonance imaging (fMRI). The first technique was used in experiments 1 to 3 , wherease the latter was applied in experiments 4 and 5. In all experiments but one, subjects performed the task with the right hand; in experiment 2, subjects traced the mazes with the left hand. Adults (experiments 1 to 4 ) as well as children (experiment 5) were scanned. Results from these experiments clearly showed the involvement of cerebellar areas in procedural motor learning.

\section{METHODS}

\section{Subjects}

Cerebellar activations were measured in a total of 36 subjects. In experiments 1 to 3 , eight subjects were tested in each experiment (five females and three males, mean age 26 in experiment 1 ; five females and three males, mean age 23 in experiment 2; and four females and four males, mean age 24 in experiment 3 ). As for experiments 4 and 5, six subjects were tested in each experiment (four females and two males, mean age 23 years in experiment 4; and four girls and two boys, aged 7, 8, 9, 10,11 , and 12 years, in experiment 5).

All subjects were tested for handedness on the Edinburgh handedness inventory 29 and were shown to be strongly right handed. None of the subjects showed any motor problems or had a history of neurological disorders. The Human Studies Committee and for the PET experiments also the Radioactive Drug Research Committee of 
Washington University approved the study. Informed consent conforming to the guidelines and procedures set forth by these committees was obtained from all subjects (and/or one of the parents/caretakers of the children in experiment 5). All subjects were paid for participation.

\section{MATERIAL}

Data regarding performance on a square design and two maze designs (FIG. 1) are reported in this paper. The square consisted of four segments, whereas the maze designs consisted of eight line segments that were connected by intersections. Selecting a wrong turn at an intersection led to a dead end. The length of each dead end path was $0.5 \mathrm{~cm}$. Total (correct) path length of the mazes and squares was $24 \mathrm{~cm}$. All designs formed closed loops, that is, the end-point of one loop was the starting point of the next loop. Subjects were instructed to move continuously with a pen through the designs with their eyes closed. Mazes and square were reverse-embossed patterns, with cutout paths for the pen to traverse. Depth of each path was $0.15 \mathrm{~cm}$ in the experiments including adult subjects and $0.30 \mathrm{~cm}$ in the experiment with the children. The latter was done to prevent the children from jumping out of the designs. In experiments 1 to 3, two maze versions were used, versions A and B, with version B being a 90 -degree rotation of version $\mathrm{A}$. One version was traced during naive and practiced performance, the other version during novel performance, with the version of maze presentation counterbalanced across subjects (FIG. 1).
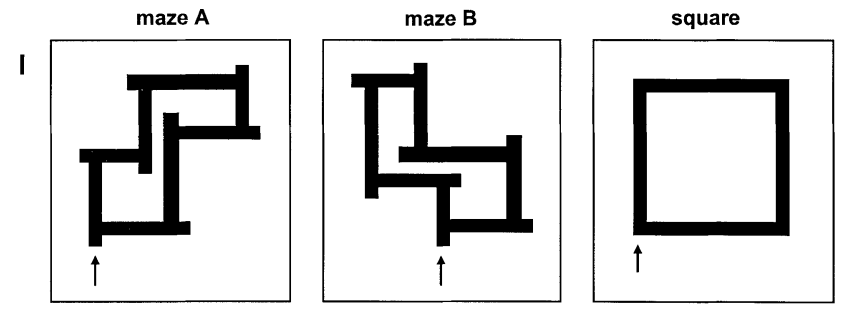

II
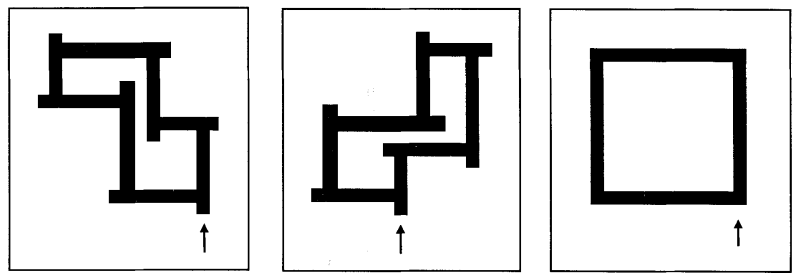

FIGURE 1. Designs used in the experiments. Arrows indicate the starting position for each design. I. Designs used in experiments $1,3,4$, and 5 , in which subjects traced the designs with the right hand in a clockwise direction. II. Designs used in experiment 2 in which subjects performed the task with the left hand in a counterclockwise direction. 


\section{Task Description}

As stated before, tracing of the designs was done with the eyes closed. Subjects were not allowed to inspect the maze designs visually or tactilely. The experimenter guided the hand of the subject that held the pen into the proper starting position of the maze. Subjects were instructed that the first movement was upwards, that they had to move continuously through the designs, and that they should try to avoid retracing a path. For most conditions the instruction to the subjects was to trace the designs as quickly and accurately as possible. To explain the task and the two-choice principle at intersections, an example maze was shown to the subjects before they were placed in the scanner. In experiments $1,3,4$, and 5, subjects were instructed to perform the tracing with the right hand in a clockwise direction; in experiment 2, tracing had to be done with the left hand in a counterclockwise direction. The pen was kept on the writing tablet or writing table during each scan.

In the PET experiments, subjects traced the designs on a Calcomp 2500 digitizer using a specially designed pen, ${ }^{30}$ both of which were connected to a Gateway 2000 $\mathrm{PC}$ in order to record the $\mathrm{X}$ - and Y-coordinates of the pen movements. Recording was done at a frequency of $100 \mathrm{~Hz}$ and a precision of $1 \mathrm{~mm}$. The digitizer was placed on an adjustable table at the right or left side of the subject (see also Ref. 31). Subjects traced the designs continuously for 1 minute during the experimental conditions and were verbally instructed when to start and to stop tracing.

In the fMRI experiments, subjects used a fiberoptic light pen and traced the designs on a Plexiglas table. Pen and table were specifically designed for the motor learning experiments. The table was positioned over the subject's upper/middle body and fitted in slots on both sides of the scanner bed, assuring stability. Height and angle of the tabletop could be adjusted, assuring a comfortable position for each subject. The maze and square designs were cutout designs in Plexiglas blocks, which fitted in special slots in the table. Only one design was in the table slot during a particular run. When needed, the experimenter changed the design between runs. Subjects traced the designs continuously for 30 seconds during experimental blocks and were verbally instructed when to start and to stop tracing. Subjects received the instructions through headphones that they were wearing in order to dampen the loud noises generated by the scanner. Because the tabletop was positioned under an angle and was translucent (as were the maze and square designs), the trajectory of the moving light dot (produced by the light pen) was visible. To make detection of the light dot possible, all lights in the scanner room were turned off. The light dot was recorded on high quality videotape with a videocamera positioned outside the scanner room in front of the window between control and scanner rooms. With special software designed at the Washington University Neuroimaging Laboratory the X- and $\mathrm{Y}$-coordinates of the videotaped light dot were recorded with a frequency of $60 \mathrm{~Hz}$ and a precision of $1 \mathrm{~mm}$. No metal parts were used for the tracing setup in the scanner room, thus minimizing the conduction of electrical noise into the scanner bore and room and possibly degradation of the MR signal.

\section{TASK PROCEDURE}

Although in some experiments additional conditions were performed, in this report behavioral and imaging data are presented while subjects performed under the 
following conditions:

initial unpracticed maze tracing (NAIVE);

first training trial on the same maze (TRAIN1);

second training trial on the same maze (TRAIN2);

third training trial on the same maze (TRAIN3);

fourth training trial on the same maze (TRAIN4);

after 5 to 10 minutes of practice on the same maze (PRAC);

following practice, but tracing a novel maze (NOVEL);

tracing a square at high speed (SQ FAST);

tracing the same square at low speed (SQ SLOW); and

holding the pen in their hand without moving it (REST).

(For a more detailed description of the conditions, see Ref. 31). TABLE 1 presents an overview of the conditions that were used in each experiment. As can be seen, the naïve, practiced, and square fast conditions were used in all experiments. In the PET experiments, subjects traced the designs continuously for 1 minute; in the fMRI experiments, tracing was done continuously in blocks of 30 seconds.

The square design was included in the experiments as a control condition, because it is motorically familiar and quickly "learned." 32 Great differences in movement speed between the naive and practiced maze conditions as well as in somatosensory feedback were expected. To make sure that differences in brain activations were not mainly related to changes in speed and somatosensory processes, subjects were instructed to trace the square as fast as possible (square fast condition) and to perform the square tracing slowly and to change direction only after bumping into the sides at the end of each segment (square slow condition). Regarding speed and somatosensory feedback, the slow square tracing would be comparable to naive maze tracing, while practiced maze tracing would be comparable to fast square tracing. As for the children, they had practiced the square already outside the scanner and during a practice session in the mockup scanner and were therefore also very familiar with the design.

In experiments 1,2 , and 5 in which subjects were not scanned during training trials, subjects practiced the same maze as they had traced in the naive condition for about 10 minutes during the interval between scans or runs. Resting periods were included during this practice interval to prevent subjects from slowing down as an effect of fatigue (TABLE 1).

\section{Imaging Procedure}

In both PET and fMRI experiments, subjects were positioned in the scanner in a supine position on an adjustable scanner table. An individually molded thermoplastic mask was securely and closely fit over the subject's face to minimize head movement during the experiments. To also minimize movement of the upper arm and shoulder, the arm that was used to perform the tasks was fixed with straps at the upper arm (PET experiments) or was supported by padding (fMRI experiments).

\section{PET Imaging}

The standard PET scanning activation method developed at Washington University ${ }^{33-38}$ was used in the three PET experiments using a Siemens-CTI 953B 
TABLE 1. Conditions during which subjects were scanned (indicated by $X$ ) for the five experiment

\begin{tabular}{cccccccccc}
\hline & \multicolumn{10}{c}{ Conditions } \\
\cline { 2 - 9 } Exp. & Naive & Train1 & Train2 & Train3 & Train4 & Prac & Novel & Sq.fast & Sq.slow \\
\hline 1 & $\mathrm{X}$ & & & & & $\mathrm{X}$ & $\mathrm{X}$ & $\mathrm{X}$ & $\mathrm{X}$ \\
2 & $\mathrm{X}$ & & & & & $\mathrm{X}$ & $\mathrm{X}$ & $\mathrm{X}$ & $\mathrm{X}$ \\
3 & $\mathrm{X}$ & $\mathrm{X}$ & $\mathrm{X}$ & $\mathrm{X}$ & $\mathrm{X}$ & $\mathrm{X}$ & $\mathrm{X}$ & $\mathrm{X}$ & \\
4 & $\mathrm{X}$ & $\mathrm{X}$ & $\mathrm{X}$ & $\mathrm{X}$ & $\mathrm{X}$ & $\mathrm{X}$ & & $\mathrm{X}$ & $\mathrm{X}$ \\
5 & $\mathrm{X}$ & & & & & $\mathrm{X}$ & & $\mathrm{X}$ & \\
\hline
\end{tabular}

Note: Trainx, training $\mathrm{x} ;$ Prac $=$ practiced, Sq. fast $=$ square fast; Sq. slow $=$ square slow.

PET scanner that collected data in three-dimensional mode for 31 axial planes with center-to-center slice separation of $3.38 \mathrm{~mm}$ (see also Ref. 31). Subjects were positioned in the scanner so that the lower two thirds of the brain was scanned, thereby insuring coverage of the entire cerebellum.

A venous catheter was inserted in either the left (experiments 1 and 3 ) or the right arm (experiment 2) to administer water labeled with the positron-emitting oxygen isotope ${ }^{15} \mathrm{O}$ acting as a blood-flow tracer, which was given as a bolus of $8-10 \mathrm{~mL}$ of saline containing $15 \mathrm{mCi}$. Blood flow was measured as an indirect marker of neuronal activation. As soon as the bolus had entered the brain, a 40-second scan was started. Between scans, an interval of 10 minutes was inserted to allow radioactivity levels to return to baseline. During each experimental scan, subjects traced the designs for a period of 1 minute, starting 10 seonds before and finishing 10 seconds after each scan.

\section{FMRI Imaging}

MRI scans were obtained on a Siemens 1.5-Tesla Vision System (Erlangen, Germany) using the blood oxygenation level-dependent (BOLD) contrast method as an indirect marker of neuronal activation. A high resolution sagittal MP-RAGE T1weighted sequence was used to acquire structural images with a voxel size of $1.25 \times$ $1 \times 1 \mathrm{~mm}$. Functional images were collected in runs with the use of an asymmetric spin-echo-planar imaging (EPI) sequence sensitive to BOLD contrast ${ }^{39,40}$ (TR = $\left.2,400 \mathrm{~ms}, \mathrm{~T} 2 *=50 \mathrm{~ms}, \alpha=90^{\circ}\right)$. During each functional run, 118 sets of $16 \mathrm{con}-$ tiguous, axial images were acquired, $8 \mathrm{~mm}$ thick, resulting in a $3.75 \times 3.75 \mathrm{~mm}$ inplane resolution. These images were acquired parallel to the anteroposterior commissure plane, offering coverage of the whole brain at a high signal-to-noise ratio. ${ }^{41}$ Each functional run was examined for motion artifacts and automatically corrected for movement within and across runs. ${ }^{42}$

Each run consisted of 5 off blocks (rest), during which the subject was holding the pen in the design without moving it, and 4 on blocks (tracing), during which they traced the design. Each block lasted 30 seconds. Each run started and ended with a rest block and lasted approximately 4.5 seconds. Between runs there was an interval of approximately 5 minutes during which the experimenter could change the designs when needed. 
Before the scanner was turned on, subjects were given complete instructions on the task. During each run, verbal instructions to either "start tracing" or "stop tracing" were given to the subjects at the beginning and end of each experimental block through headphones. In experiment 4 in the square conditions, the instruction was either to "start tracing fast" or "start tracing slow" in those instances in which subjects had to trace the square at high or low speed.

In experiment 5, each child underwent a training session in a special mock-up scanner 1-6 days before the actual fMRI scanning session, during which they could get accustomed to the scanner environment and scanner noises and practiced the procedure of stopping and starting while tracing the square with their eyes closed. No maze designs were used in the mock-up training sessions.

\section{DATA ANALYSIS}

\section{Behavioral Performance}

In the PET experiments, data records for all conditions were low-pass filtered at $10 \mathrm{~Hz}$ and the drawing trajectories were displayed on a computer screen. The beginning and end of the 1-minute tracing movement was determined by means of an interactive computer program.

In the fMRI experiments, the drawing trajectories were displayed on a computer screen using OASIS $6.0,{ }^{43}$ and the beginning and end of each 30 -second tracing period was determined. In all experiments, mean velocity as well as the number of errors per loop was calculated for each tracing period. Tracing a dead-end path or retracing (part of) a segment was counted as an error. ${ }^{32}$ Repeated measurement ANOVA's were performed to study effects of condition for velocity and errors (superANOVA, version 1.1, Abacus Concepts). Probabilities were adjusted using the Greenhouse-Geisser epsilon.

\section{Imaging Experiments}

PET images were reconstructed with filtered back projection. A Butterworth 0.5 filter with an order of 5 was used, producing a transaxial resolution of $14 \mathrm{~mm}$ full width at half maximum. Linear normalization was applied to the smoothed images. Furthermore, due to sampling characteristics of the PET scanner resulting in much noisier uppermost and lowermost slices than those in the center, 7 slices from the top and bottom were excluded from further analysis.

The fMRI images were realigned and normalized to a common mode. The fMRI data were analyzed using an implementation of the general linear model. For the analysis in experiment 4 , data of two blocks of 30 seconds were combined. Therefore, run 1 included the naive and first training condition, run 2 the second and third training condition, whereas run 3 contained the fourth training and the practiced condition. In the square fast and square slow conditions, only data from the first two blocks were used for the analysis. In experiment 5, four blocks were combined in each condition.

For each subject, images were grouped into reference-control pairs with the rest condition being subtracted from one of the experimental conditions (in the PET ex- 
periments) or the off blocks being subtracted from the on blocks (in the fMRI experiments). No excessive movement artifacts were found in any of the subtracted image pairs. All subtraction images were transformed into stereotaxic space defined in Talairach and Tournoux's atlas ${ }^{44}$ based on a lateral skull X-ray (PET experiments) or MPRAGE (fMRI experiments). In each experiment, images acquired during identical conditions were averaged across subjects to improve the signal-to-noise ratio. In the next step a composite, summed difference image was created for each experiment that included all the experimental conditions or on-blocks minus their rest condition or off-blocks. A maximum-detection algorithm was used to identify positive local maxima in the summed image that recorded the maxima by location in stereotaxic coordinates and by magnitude. For the cerebellar regions reported in this paper, for each subtraction the magnitude was calculated per region and per subject. Repeated measurement ANOVA's were performed on all conditions for the magnitudes in each cerebellar region. Probabilities were adjusted using the GreenhouseGeisser epsilon.

\section{RESULTS}

\section{Behavioral Data}

As can be seen in TABLE 2 and Figure 2, in all experiments the speed at which the mazes were traced increased significantly with practice. It is also clear that all subjects performed the fast square tracing at high speed while tracing at a slow speed in the square slow condition. In all five experiments a significant effect of condition was found for mean velocity $(p<0.001)$. Furthermore, the velocity during practiced and square fast tracing was significantly higher $(p<0.01)$ than during naive, novel, and square slow tracing. The only exception was found in experiment 5 . The speed with which the children traced the practiced maze was not significantly faster than the speed during naive tracing. Tracing during square fast, however, was. FIGURE 2 and TABLE 2 show also that in all experiments, practice resulted in more accurate performance. Practiced maze tracing showed a significant decrease in the number of errors compared to naive or novel maze tracing. Also for errors the effect of condition was significant $(p<0.01)$. None of the adults made any errors in the square conditions. This was in contrast to the children who made some errors in the square fast condition. However, it was only in a few instances that they retraced a segment in the square (TABLE 2 and FIG. 2).

\section{Neuroimaging Data}

Three cerebellar areas showed conditional effects in all experiments. An area in the left lateral cerebellum showed activations that were related to practice, with high activations found in naive and novel conditions, whereas activations were significantly less after practice and in any of the simple over-learned square conditions (FIG. 3, upper graph). That this change in activation was not related to changes in velocity can be seen in FIGURE 3, upper graph, when comparing left cerebellar activations in both square conditions. Although the velocity was almost four times as high in the square fast condition, left cerebellar activations were more or less the same in both square conditions. In all five experiments a significant effect of condi- 


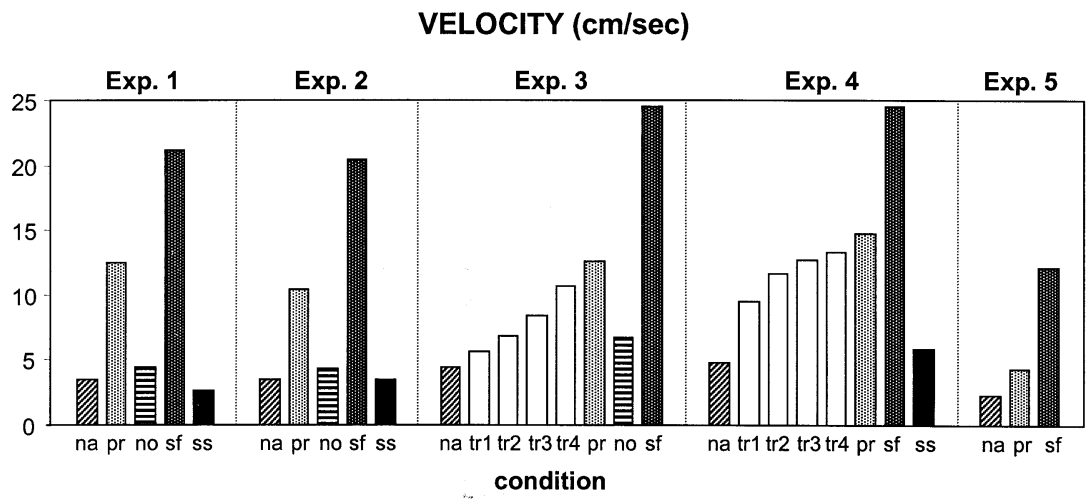

ERRORS PER LOOP

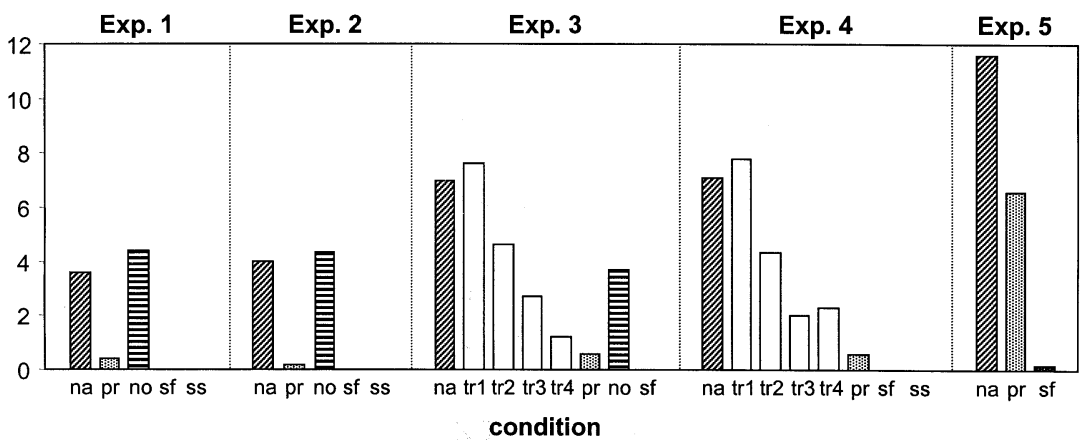

FIGURE 2. Mean velocity (upper graph) and number of errors per loop (lower graph) for each experiment as a function of condition.

tion was found on the magnitudes $(p<0.05)$. Skilled performance activated the left cerebellum significantly less than did unskilled performance. In experiments 3 and 4 in which subjects were also scanned during practice, the decrease in activation in the left cerebellum over the six practice conditions (naive, training 1-4, and practiced tracing) correlated significantly $(p<0.01)$ with the decrease in errors in these conditions, with a correlation of 0.92 in experiment 3 and 0.83 in experiment 4 (FIGS. 2 [lower graph] and 3 [upper graph], the first six columns in the graphs of experiments 3 and 4).

An area in the right lateral cerebellum showed an effect that might be related to timing requirements. As can be seen in FIGURE 3, middle graph, in those conditions in which subjects received the instruction to perform the task as quickly as possible, in the naive, novel, training, practiced, and square fast conditions, this area in the right cerebellum was highly activated. Only under the condition in which subjects did not receive the instruction to perform at high speed, the square slow condition, right cerebellum, was significantly less activated (FIG. 3, middle graph, black bars). 


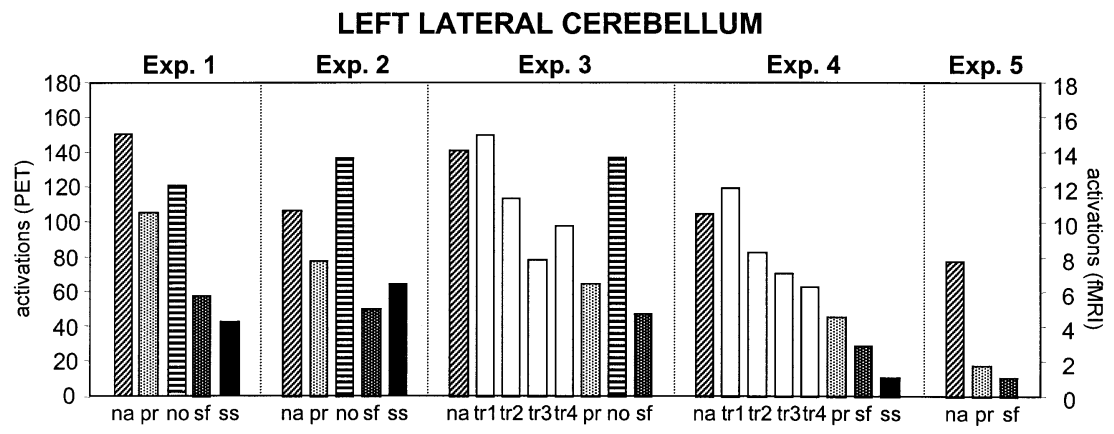

RIGHT LATERAL CEREBELLUM

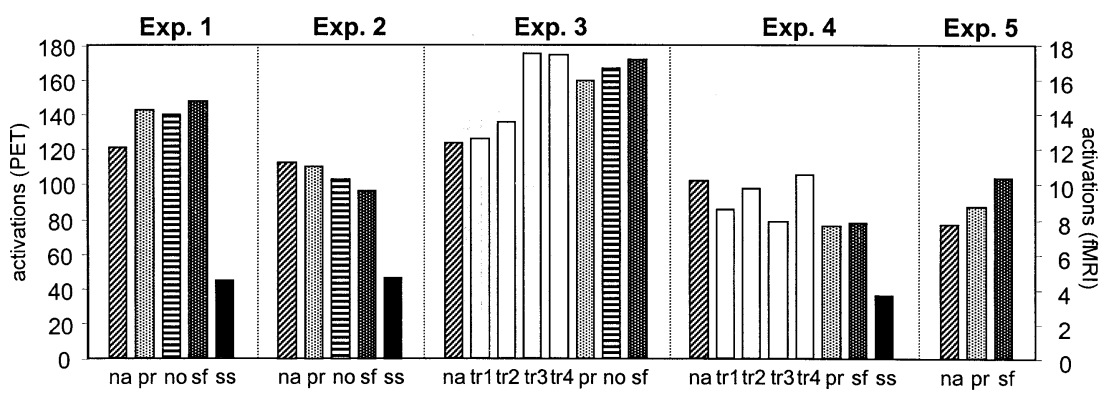

IPSILATERAL VERMIS

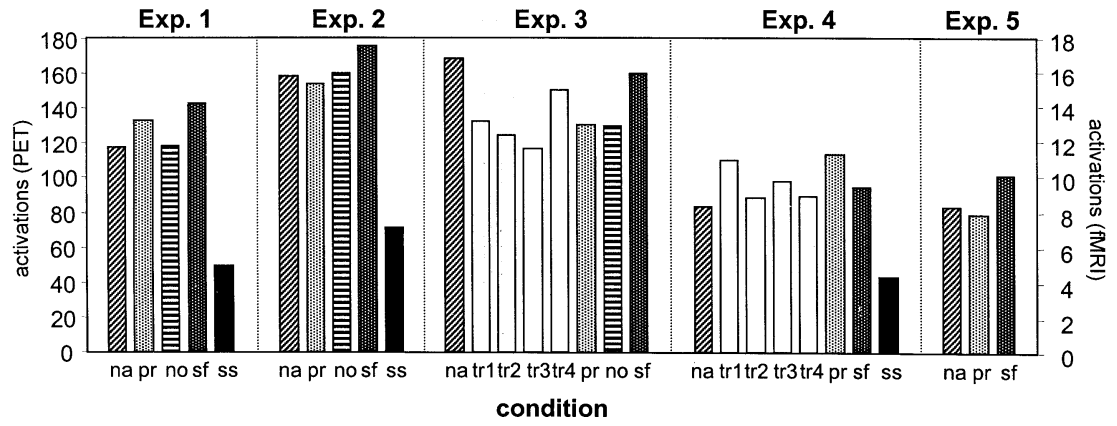

FIGURE 3. Activations in left lateral cerebellum (upper graph), right lateral cerebellum (middle graph), and ipsilateral cerebellar vermis (lower graph) for each experiment as a function of condition. (For coordinates, see TABLE 2.)

As expected, only in the experiments that included the square slow condition (experiments 1,2 , and 4$)$ was a significant effect of condition measured $(p<0.05)$.

A second cerebellar area that showed the same "timing" effects as those found in the right lateral cerebellum was observed in the anterior vermis, ipsilateral to the hand of performance (FIG. 3, lower graph). Also in this area, all conditions resulted 
TABLE 2. Values of dependent variables (velocity and errors) and magnitudes in cerebellar areas per experiment and condition

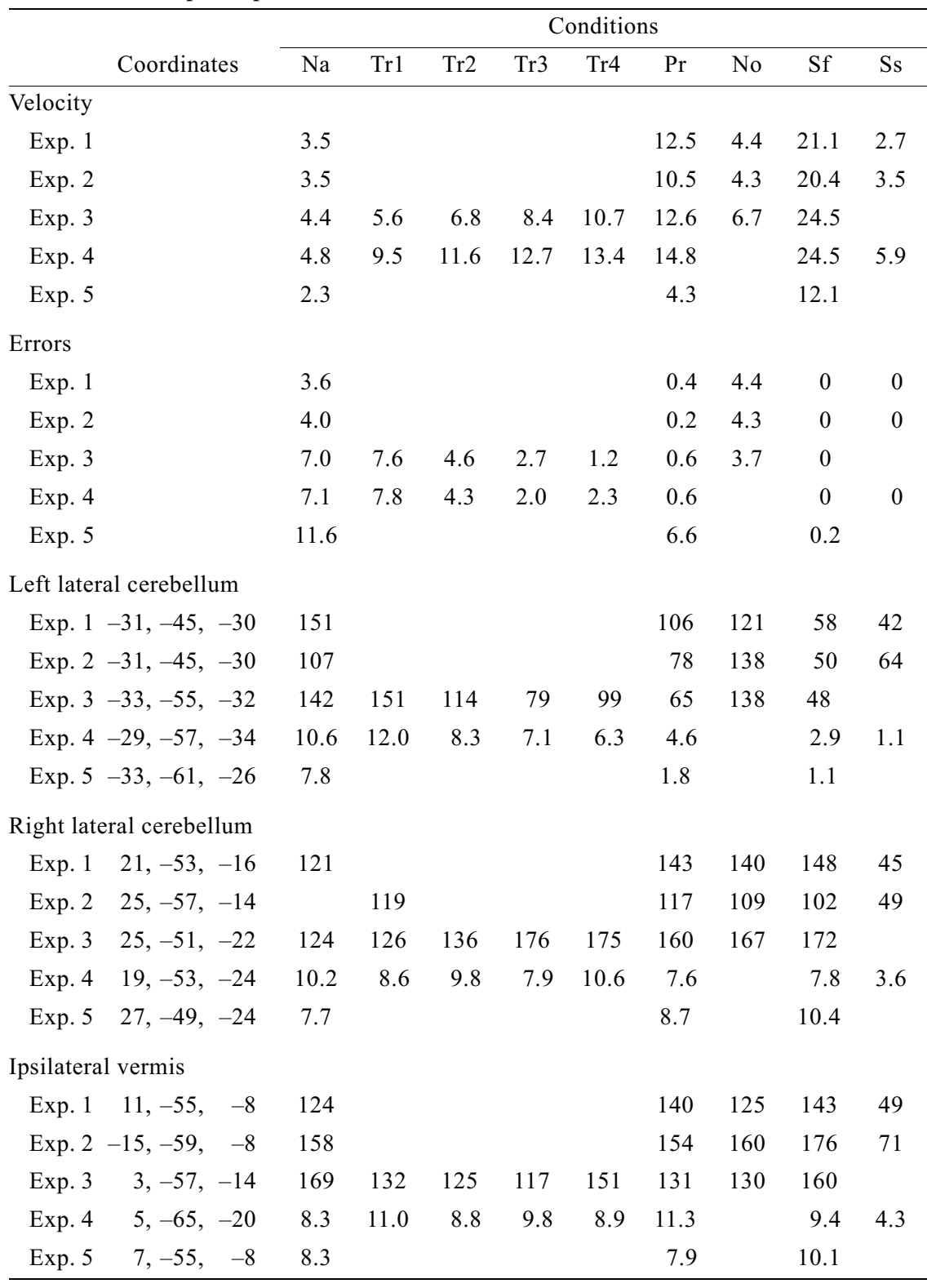

Note: Coordinates are given in Talairach ${ }^{44}$ format in the order $\mathrm{x}, \mathrm{y}$, and $\mathrm{z}$, where $\mathrm{x}$ is the lateral displacement from the midline ( - for left hemisphere); $y$ is the anteroposterior displacement relative to the anterior commissure ( - for positions posterior to this); and $\mathrm{z}$ is the vertical position relative to the AC-PC line ( - if below this line). Exp. X, Experiment X; Na, naïve; TrX., training X; Pr, practiced, No, novel; Sf, square fast; Ss, square slow. 


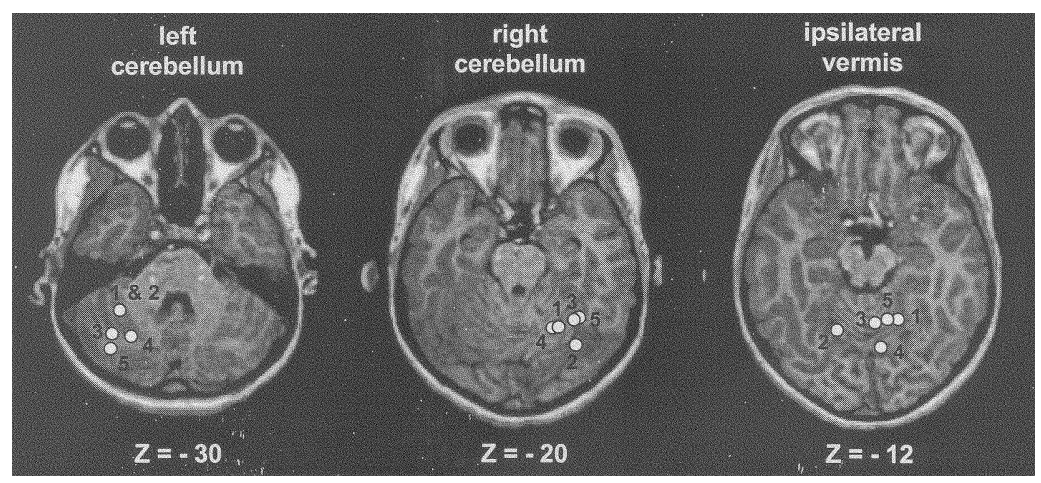

FIGURE 4. Cerebellar activations of all five experiments overlaid on horizontal anatomical images, shown in Talairach space with the z-coordinate label. Left in the images corresponds to left and top to frontal.

in high activations, except again in the square slow condition. Again, a significant conditional effect was only found in the experiments that included the square slow condition $(p<0.05)$.

As can be seen in TABLE 2 and Figure 4, activations in the aforementioned cerebellar areas were observed in almost the same location in all five experiments. An ANOVA comparing the $\mathrm{x}, \mathrm{y}$, and $\mathrm{z}$ coordinates in all five experiments showed that they could not be significantly distinguished from each other $(p=0.46$ for the left cerebellum; $p=0.26$ for the right cerebellum; and $p=0.45$ for cerebellar vermis. (For analysis in vermal coordinates, all $\mathrm{x}$ coordinates were assumed to be located in the same hemisphere).

Note that the only cerebellar area that showed a lateralized activation was the vermis. This area was activated ipsilateral to the hand with which the task was performed. Left and right lateral cerebellum showed activations that were independent of the hand used and most likely reflect processing at a more abstract level (FIGS. 3 and 4).

\section{DISCUSSION}

The results of the five experiments described in this paper clearly show that the cerebellum is involved in sequential motor learning. Performing the same task, in all five experiments the same cerebellar areas were activated. However, these areas showed differential conditional effects. Left lateral cerebellum showed effects that were related to practice, with lower activations during practiced and over-learned performance. Right lateral cerebellum and ipsilateral vermis were activated to almost the same extent in all maze conditions and square fast tracing, with only significantly less activation observed during square slow tracing. These cerebellar changes were measured with PET as well as fMRI and were found in adults as well as in children, stressing the robustness of these findings. These findings are in agree- 
ment with the results reported in an fMRI study by Cui et al. ${ }^{45}$ in which subjects performed a delayed sequential finger movement task with the right hand. The authors report activation in lateral cerebellum in both hemispheres. As in our experiments, subjects in this study were instructed to perform the sequence, which was presented in advance of an imperative signal, as quickly as possible, which might suggest involvement of the right cerebellum. The sequence of the required movements changed on each trial, resulting in the production of rather unpracticed sequences. This might suggest involvement of the left cerebellum.

To trace the maze accurately, skillfully, and smoothly, errors need to be detected and corrected, the correct sequence of the segments has to be learned, and the appropriate velocities and movement timings need to be produced. Therefore, error detection, sequential, spatial, and timing aspects (as well as other types of information, e.g., visualization, somatosensory feedback, memory, and muscle agonist-antagonist pairing) all may play a role. Results from the experiments that we report in this paper suggest that the cerebellar involvement in motor learning in the maze task is most likely related to errors and timing aspects.

\section{Learning-Related Effects in the Left Lateral Cerebellum}

There is little doubt that the cerebellum is involved in motor learning, even the simplest types of motor learning. Increased activation in the left cerebellum during early learning in the naive and novel conditions and decreased activation in this area when the task was learned or when an over-learned square was traced clearly indicate the role of the cerebellum in procedural learning. This role is also emphasized by studies involving cerebellar patients that reported impaired motor learning in these patients. ${ }^{46-48}$ Molinari and colleagues ${ }^{49}$ have shown that patients with left cerebellar lesions were more impaired on a procedural motor learning task than were patients with right cerebellar lesions, supporting the findings of left cerebellar involvement in our motor learning task. Furthermore, Molinari's patients were impaired on the task during both right- and left-hand performance. This finding is consistent with our data showing left cerebellar activation with both right- and lefthand performance during naive and novel maze tracing. When Gebhart and Thach ${ }^{50}$ tested left cerebellar patients using our maze and square designs, they observed impaired learning on the maze task compared to that of controls. Patients showed less improvement and more errors. On the other hand, repeated tracing of the square design showed a learning effect in the patients that was comparable to that of the controls.

Evidence that the cerebellum plays a role in motor learning also comes from animal studies. Lalonde and Botez ${ }^{51}$ found that animals with cerebellar damage were impaired on maze learning. Rats who had observed 200 Morris water maze trails performed by companion rats before undergoing hemicerebellectomy displayed no spatial deficits and normal exploration abilities comparable to those of control rats. This contrasts with the performance of rats who had undergone hemicerebellectomy before observation training. ${ }^{52}$ These rats showed a complete lack of learning.

Involvement of the cerebellum during motor learning tasks was also shown in several other imaging studies. Although some studies showed increased cerebellar activation as an effect of practice, ${ }^{53-55}$ other studies showed a decrease in cerebellar activations following learning and practice of a motor task. ${ }^{56-60}$ Furthermore, in an 
experiment in which subjects were tested on a perceptual maze with little pre-training, activations were also observed in the left cerebellum. ${ }^{61}$

The high correlation between decreases in left cerebellar activations and decreases in errors over the course of practice in experiments 3 and 4 suggests that activation in the left cerebellum might be related to error detection and correction. Increased cerebellar activity related to performance errors during naive performance or early on during learning has been observed in other imaging studies. ${ }^{23,56,58,62}$ The patients with left cerebellar damage tested by Gebhart and Thach ${ }^{50}$ on the maze task showed only a moderate decrease in errors, quite different from the control subjects who showed a decrease comparable to that of subjects in our experiments 3 and 4 . Fiez et al. ${ }^{2}$ described a right cerebellar patient who hardly showed any decrease in errors on a verb generation task, a task that is known to engage the right cerebellum. ${ }^{63}$ Furthermore, several theoretical models suggest involvement of the cerebellum in errorbased learning. ${ }^{24,64,65}$

Our data as well as the aforementioned studies suggest a specialized role for the cerebellum in motor learning. As Thach states in his 1998 paper, 66 the "cognitive" cerebellum might be involved in movement planning, learing new movements, and keeping track of movement errors.

\section{Timing-Related Effects in Ipsilateral Vermis and Right Lateral Cerebellum}

The finding that the ipsilateral vermis and right lateral cerebellum were activated to more or less the same extent in all maze conditions as well as the square fast condition suggests that these areas are somehow or other involed in performance under speed instructions. In all these conditions the instruction was to perform as quickly as possible. This in contrast to the instruction during the square slow condition, where subjects were explicitly instructed to perform the task slowly and only change direction when a forced stop was experienced when the subject bumped into one of the sides. In this condition no acceleration and deceleration pattern had to be learned or used in order to move fast and smoothly through the design. In the other conditions, however, a precise timing of accelerations and decelerations is needed to produce the appropriate velocity to trace the designs as quickly as possible and to avoid bumping into the side. It is likely that this velocity-based acceleration/deceleration timing pattern might be controlled by the ipsilateral vermis and right lateral cerebellum. Research findings indeed suggest involvement of the cerebellum in the control of movement velocity. ${ }^{67}$ It also has been shown that patients with cerebellar lesions have impairments regarding movement velocity and acceleration. ${ }^{68,69}$ Furthermore, research with cerebellar patients also has demonstrated that these patients have deficits in velocity perception. ${ }^{70,71}$

In order to carry out well-learned skilled movements, especially when they are performed quickly and more or less amtomatically, it seems crucial that these movements need to be organized with correct timing. It is hypothesized that the cerebellum performs this task by sending trigger signals to the motor cortex ${ }^{72}$ Research with cerebellar patients also suggests a role for the cerebellum in the timing of coordinated movements. ${ }^{73}$ Deficits in the temporal coordination of internally generated multijoint movement sequences have been observed in cerebellar patients. ${ }^{74,75}$

Results from brain imaging studies have linked the control of motor timing to lateral and vermal cerebellum. Reproducing rhythms of increasing temporal complex- 
ity that were presented separately in auditory and visual modalities resulted in PET activation of both lateral cerebellar cortex and cerebellar vermis. ${ }^{27}$ In another imaging study, subjects were imaged using fMRI during synchronization and continuation of a paced finger-tapping task. ${ }^{76}$ In this study, tapping with the right finger resulted in activations in right lateral cerebellum and vermis. Lateral cerebellar activations also were observed in another fMRI study in which subjects performed a memory-timed finger movement task. ${ }^{77}$

Although both lateral and vermal cerebellum seem to be involved in motor timing, it seems unlikely that they are involved in the same timing processes. Animal and human lesion studies suggest a differential contribution of medial and lateral cerebellum in motor timing. A study with rats showed differential effects of midline and lateral cerebellar lesions. While midline lesions resulted in deficits in motor coordination, lesions in lateral areas showed deficits in spatial orientation. ${ }^{78}$ However, in this study lesions were bilateral, and lateral lesions included the cerebellar hemispheres and dentate nucleus. A follow-up study with rats, in which the dentate nucleus was selectively lesioned, ${ }^{79}$ showed the same deficit in spatial orientation.

The fact that in our experiments the vermis was activated ipsilateral to the hand that was used to perform the tasks (right vermis in experiments 1,3,4, and 5, and left vermis in experiment 2) suggests that this vermal activation might be related to timing aspects involved in motor execution. A study ${ }^{80}$ involving patients with cerebellar lesions in either the medial zone of the cerebellum or the lateral cerebellum reported that all patients showed an increased variability in a repetitive tapping task; however, this variablity was attributable to different processes. While patients with lateral lesions showed a deficit in central timing processes as to determine when a response should be made, patients with lesions in the medial area showed a variance related to motor processes, most likely showing an impairment in the implementation and execution of the timed response. Results of a more recent study ${ }^{81}$ regarding lateral and vermal cerebellar involvement in temporal processing support the data by Ivry et al. ${ }^{80}$ mentioned earlier. When comparing cerebellar vermis-lesioned and cerebellar hemisphere-lesioned rats on a temporal discrimination task, ${ }^{82}$ it was observed that only the rats with lesions in the cerebellar hemisphere showed deficits in perceptual timing. Neuroimaging data with respect to cerebellar activations also provided results supporting differential roles for vermis and lateral cerebellum in motor timing. ${ }^{83,84}$ In a PET study in which subjects performed a visuomanual tracking task by tracking a moving target at different rates, it was found that activation in ipsilateral anterior vermis correlated with the rate of movement, implicating this area in the control of low-level kinematic or dynamical parameters of movement execution. ${ }^{83}$ An fMRI study in which subjects perceived visual and auditory rhythms but no motor response was made during scanning, showed that only lateral cerebellum was activated, no activation in medial areas was found, ${ }^{84}$ again suggesting that activations in the vermis are most likely related to motor execution.

Movement timing is one of the processes involved in motor control. More and more evidence supports the view that the cerebellum plays an important role in this process. Research data also suggest that different cerebellar areas control different aspects of motor timing. Although the exact role of different cerebellar regions in motor timing is not known, it seems that the vermis is most likely involved in lower processes of motor timing, like the execution of timed movements, while the lateral cerebellum appears to play a role in the cognitive aspects of motor timing. 


\section{Comparisons between PET and fMRI}

As for comparisons between the two imaging techniques, PET and fMRI, several studies that compared both techniques directly, either in different subjects focusing on a specific cortical area ${ }^{85,86}$ or in the same subjects focusing on the whole brain, ${ }^{87}$ have shown good colocalization of the activations obtained with both techniques. Our data regarding cerebellar areas confirm these results and are consistent with the right lateral cerebellar activation observed in subjects who performed self-paced right index finger movements during PET and fMRI scanning. ${ }^{87}$ We can add to these findings that there is also good colocalization between cerebellar activations in children and adults.

\section{CONCLUSION}

The results from our experiments might be helpful in understanding the role of the cerebellum in motor learning especially regarding the cognitive aspects involved in motor learning. The differential activations in different cerebellar areas support the hypothesis that the cerebellum is most likely involved in several functions ${ }^{88}$ that might be controlled by different cerebellar areas. Each area seems to be specialized for a specific aspect of motor learning.

\section{REFERENCES}

1. Wallesch, C.W. \& A. Horn. 1990. Long-term effects of cerebellar pathology on cognitive functions. Brain Cogn. 14: 19-25.

2. Fiez, J.A., S.E. Petersen, M.K. Cheney \& M.E. Raichle. 1992. Impaired non-motor learning and error detection associated with cerebellar damage. A single case study. Brain 115: 155-178.

3. Silveri, M.C., A.M. Di BettA, V. Filippini, et al. 1998. Verbal short-term storerehearsal system and the cerebellum. Evidence from a patient with a right cerebellar lesion. Brain 121: 2175-2187.

4. Timmann, D., J. Drepper, M. Maschke, et al. 2002. Motor deficits cannot explain impaired cognitive associative learning in cerebellar patients. Neuropsychologia 40: $788-800$.

5. Levisohn, L., A. Cronin-Golomb \& J.D. Schmahmann. 2000. Neuropsychological consequences of cerebellar tumour resection in children: cerebellar cognitive affective syndrome in a paediatric population. Brain 123: 1041-1050.

6. Riva, D. \& C GIORGI. 2000. The cerebellum contributes to higher functions during development: evidence from a series of children surgically treated for posterior fossa tumours. Brain 123: 1051-1061.

7. Middleton, F.A. \& P.L. Strick. 1994. Anatomical evidence for cerebellar and basal ganglia involvement in higher cognitive function. Science 266: 458-461.

8. MiddLeton, F.A. \& P.L. STRICK. 1998. Cerebellar output: motor and cognitive channels. Trends Cogn. Sci. 2: 348-354.

9. Middleton, F.A. \& P.L. STRick. 2001. Cerebellar projections to the prefrontal cortex of the primate. J. Neurosci. 21: 700-712.

10. Cabeza, R. \& L. Nyberg. 2000. Imaging cognition II: An empirical review of 275 PET and fMRI studies. J. Cogn. Neurosci. 12: 1-47.

11. Decety, J., H. Sjoholm, E. Ryding, et al. 1990. The cerebellum participates in mental activity: Tomographic measurement of regional cerebral blood flow. Brain Res. 535: 313-317. 
12. Ryding, E., J. Decety, H. Sjoholm, et al. 1993. Motor imagery activates the cerebellum regionally. A SPECT rCBF study with 99mTc-HMPAO. Cogn. Brain Res. 1: 94 99.

13. Lotze, M., P. Montoya, M. Erb, et al. 1999. Activation of cortical and cerebellar motor areas during executed and imagined hand movements: an fMRI study. J. Cogn. Neurosci. 11: 491-501.

14. Ino, T., Y. Inoue, M. KAGE, et al. 2002. Mental navigation in humans is processed in the anterior bank of the parieto-occipital sulcus. Neurosci. Lett. 322: 182-186.

15. MARR, D. 1969. A theory of cerebellar cortex. J. Physiol. 202: 437-470.

16. AlBus, J.S. 1971. A theory of cerebellar function. Math. Biosci. 10: 22-61.

17. Raymond, J.L., S.G. Lisberger \& M.D. Mauk. 1996. The cerebellum: a neuronal learning machine? Science 272: 1126-1131.

18. Van Mier, H. 2000. "Human learning." In Brain Mapping: The Systems. A.W. Toga \& J.C. Mazziotta, Eds. : 605-621. Academic Press. San Diego.

19. Thach, W.T., H.P. Goodkin \& J.G. Keating. 1992. The cerebellum and the adaptive coordination of movement. Annu. Rev. Neurosci. 15: 403-442.

20. Goodkin, H.P., J.G. Keating, T.A. Martin \& W.T. Thach. 1993. Preserved simple and impaired compound movement after infarction in the territory of the superior cerebellar artery. Can. J. Neurol. Sci. 20: S93-104.

21. Bastian, A.J., T.A. Martin, J.G. Keating \& W.T. Thach. 1996. Cerebellar ataxia: abnormal control of interaction torques across multiple joints. J. Neurophysiol. 76: 492-509.

22. TOPKA, H., J. KonCZAK, K. SCHNEIDER, et al. 1998. Multijoint arm movements in cerebellar ataxia: abnormal control of movement dynamics. Exp. Brain Res. 119: 493503.

23. Miall, R.C., H. Imamizu \& S. Miyauchi. 2000. Activation of the cerebellum in coordinated eye and hand tracking movements: an fMRI study. Exp. Brain Res. 135: 22-33.

24. Kawato, M. \& H. Gomi. 1992. A computational model of four regions of the cerebellum based on feedback-error learning. Biol. Cybern. 68: 95-103.

25. IVRY, R.B. \& S.W. Keele. 1989. Timing functions of the cerebellum. J. Cogn. Neurosci. 1: $136-152$.

26. THACH, W.T. 1996. On the specific role of the cerebellum in motor learning and cognition: clues from PET activation and lesion studies in man. Behav. Brain Sci. 19: 411431.

27. Penhume, V.B., R.J. Zatorre \& A.C. Evans. 1998. Cerebellar contributions to motor timing: a PET study of auditory and visual rhythm reproduction. J. Cogn. Neurosci. 10: $752-765$.

28. Mauk, M.D., J.F. Medina, W.L. Nores \& T. Ohyama. 2000. Cerebellar function: coordination, learning or timing? Curr. Biol. 10: R522-525.

29. Raczkowski, D., J.W. Kalat \& R. Nebes. 1974. Reliability and validity of some handedness questionnaire items. Neuropsychologia 6: 43-47.

30. MaArse, F.J., H.J.J. Janssen \& F. DeXEL. 1988. A special pen for an XY-tablet. In Computers. In Psychology; Methods, Instrumentation, and Psychodiagnostics. F.J. Maarse, L.J.M. Mulder, W.P.B. Sjouw \& A.E. Akkerman, Eds. :133-139. Swets and Zeitlinger. Amsterdam.

31. Van Mier, H., L.W. Tempel, J.S. Perlmutter, et al. 1998. Changes in brain activity during motor learning measured with PET; effects of hand of performance and practice. J. Neurophysiol. 80: 2177-2200.

32. Van Mier, H., W. Hulstijn \& S.E. Petersen. 1993. Changes in motor planning during the acquisition of movement patterns in a continuous task. Acta Psychol. 82: 291312 .

33. Fox, P.T., J.S. Perlmutter \& M.E. Raichle. 1985. A stereotactic method of anatomical localization for positron emission tomography. J. Comput. Assisted Tomogr. 9: $141-153$.

34. Fox, P.T., M.A. Mintun, E.M. Reiman \& M.E. Raichle. 1988. Enhanced detection of focal brain responses using intersubject averaging and change-distribution analysis of subtracted pet images. J. Cereb. Blood Flow Metab. 8: 642-653. 
35. Fox, P.T. \& M.A. Mintun. 1989. Noninvasive functional brain mapping by change-distribution analysis of averaged pet images of $\mathrm{H}_{2}{ }^{15} \mathrm{O}$ tissue activity. J. Nucl. Med. 30: 141-149.

36. Herscovitch, P., J. Markham \& M.E. Raichle. 1983. Brain blood flow measured with $\mathrm{H}_{2}{ }^{15} \mathrm{O}$. I. Theory and error analysis. J. Nucl. Med. 24: 782-789.

37. Mintun, M.A., P.T. Fox \& M.E. Raichle. 1989. A highly accurate method of localizing regions of neuronal activation in the human brain with positron emission tomography. J. Cereb. Blood Flow Metab. 9: 96-103.

38. Raichle, M.E., W.R.W. Martin, P. Herscovitch, et al. 1983. Brain blood flow measured with $\mathrm{H}_{2}{ }^{15}$ O. II. Implementation and validation. J. Nucl. Med. 24: 790-798.

39. Kwong, K.K., J.W. Belliveau, D.A. Chesler, et al. 1992. Dynamic magnetic resonance imaging of human brain activity during primary sensory stimulation. Proc. Natl. Acad. Sci. USA 89: $5675-5679$.

40. OGAWA, S., D.W. TANK, R. MENON, et al. 1992. Intrinsic signal changes accompanying sensory stimulation: Functional brain mapping with magnetic resonance imaging. Proc. Natl. Acad. Sci. USA 89: 5951-5955.

41. Conturo, T.E., R.C. McKinstry, E. Akbudak, et al. 1996. Sensitivity optimization and experimental design in functional magnetic resonance imaging. Neurosci. Abstr. 22: 7.

42. SNYDER, A.Z. 1996. Difference image vs. ratio image error function forms in PET-PET realignment. In Quantification of Brain Function Using PET. R. Myers, V. Cunningham, D. Bailey \& T. Jones, Eds. :131-137. Academic Press. San Diego.

43. De Jong, W.P., W. Hulstijn, B.J.M. Kosterman \& B.C.M. Smits-Engelsman. 1996 OASIS software and its application in experimental handwriting research. In Handwriting and Drawing Research: Basic and Applied Issues. M.L. Simner, C.G. Leedham \& A.J.W.M. Thomassen, Eds. IOS. Amsterdam.

44. Talairach, J. \& P. Tournoux. 1988. Co-planar Stereotaxic Atlas of the Human Brain. Thieme. New York.

45. CUI, S.Z., E.Z. LI, Y.F. ZANG, et al. 2000. Both sides of human cerebellum involved in preparation and execution of sequential movements. Neuroreport 11: 3849-3853.

46. Sanes, J.N., B. Dimitrov \& M. Hallett. 1990. Motor learning in patients with cerebellar dysfunction. Brain 113: 103-120.

47. Pascual-Leone, A, J. Grafman, K. Clark, et al. 1993. Procedural learning in Parkinson's disease and cerebellar degeneration. Ann. Neurol. 34: 594-602.

48. Laforce, R., JR. \& J. Doyon. 2001. Distinct contribution of the striatum and cerebellum to motor learning. Brain Cogn. 45: 189-211.

49. Molinari, M., M.G. Leggio, A. Solida, et al. 1997. Cerebellum and procedural learning. Evidence from focal cerebellar lesions. Brain 120: 1753-1762.

50. Gebhart, A.L. \& W.T. Thach. 1999. Cerebellar subjects show cognitive impairments on a novel maze learning task. Neurosci. Abstr. 25: 650.

51. LALONDE, R. \& M.I. BoteZ. 1990. The cerebellum and learning processes in animals. Brain Res. Rev. 15: 325-332.

52. Leggio, M.G., M. Molinari, P. Neri, et al. 2000. Representation of actions in rats: the role of cerebellum in learning spatial performances by observation. Proc. Natl. Acad. Sci. USA 97: 2320-2325.

53. Doyon, J., A.M. Owen, M. Petrides, et al. 1996. Functional anatomy of visuomotor skill learning in human subjects examined with positron emission tomography. Eur. J. Neurosci. 8: 637-648.

54. Grafton, S.T., R.P. Woods \& M. TyszKa. 1994. Functional imaging of procedural motor learning: relating cerebral blood flow with individual subject performance. Human Brain Mapping 1: 221-234.

55. Seitz, R.J., A.G. Canavan, L. Yaguez, et al. 1994. Successive roles of the cerebellum and premotor cortices in trajectorial learning. Neuroreport 20: 2541-2544.

56. Jenkins, I.H., D.J. Brooks, P.D. NiXon, et al. 1994. Motor sequence learning: a study with positron emission tomography. J. Neurosci. 14: 3775-3790.

57. Friston, K.J., C.D. Frith, R.E. Passingham, et al. 1992. Motor practice and neurophysiological adaptation in the cerebellum: a positron tomography study. Proc. Roy. Soc. Lond.-Series B. Biol. Sci. 248: 223-228. 
58. Flament, D., J.M. Ellermann, S-G. Kim, et al. 1996. Functional magnetic resonance imaging of cerebellar activation during the learning of a visuomotor dissociation task. Human Brain Mapping 4: 210-226.

59. Toni, I., M. Krams, R. TURner \& R.E Passingham. 1998. The time course of changes during motor sequence learning: a whole-brain fMRI study. Neuroimage 8: 50-61.

60. Jueptner, M., K.M. Stephan, C.D. Frith, et al. 1997. Anatomy of motor learning. I. Frontal cortex and attention to action. J. Neurophysiol. 77: 1313-1324.

61. Ghatan, P.H., J.-C. Hsein, A. Wirsen-Meurling, et al. 1995. Brain activation induced by the perceptual maze test: A PET study of cognitive performance. Neuroimage 2: $112-124$.

62. Imamizu, H., S. Miyauchi, T. Tamada, et al. 2000. Human cerebellar activity reflecting an acquired internal model of a new tool. Nature 403: 192-195.

63. Raichle, M.E., J.A. Fiez, T.O. Videen, et al. 1994. Practice-related changes in human brain functional anatomy during nonmotor learning. Cereb. Cortex 4: 8-26.

64. Doya, K. 1999. What are the computations of the cerebellum, the basal ganglia and the cerebral cortex? Neural Networks 12: 961-974.

65. Houk, J.C., J.T. Buckingham \& A.G. Barto. 1996. Models of the cerebellum and motor learning. Behav. Brain Sci. 19: 368-383.

66. THACH, W.T. 1998. What is the role of the cerebellum in motor learning and cognition? Trends Cogn. Sci. 9: 331-337.

67. EBNER, T.J. 1998. A role for the cerebellum in the control of limb movement velocity. Curr. Opin. Neurobiol. 8: 762-769.

68. DiEnER, H.C. \& J. Dichgans. 1992. Pathophysiology of cerebellar ataxia. Mov. Disord. 7: $95-109$.

69. Hore, J., B. Wild \& H.C. DiEnER. 1991. Cerebellar dysmetria at the elbow, wrist, and fingers. J. Neurophysiol. 65: 563-571.

70. IVRY, R. \& H.C. DIENER. 1991. Impaired velocity perception in patients with lesions of the cerebellum. J. Cogn. Neurosci. 3: 355-366.

71. Nawrot, M. \& M. Rizzo. 1998. Chronic motion perception deficits from midline cerebellar lesions in human. Vision Res. 38: 2219-2224.

72. Hikosaka, O., H. Nakahara, M.K. Rand, et al. 1999. Parallel neural networks for learning sequential procedures. Trends Neurosci. 22: 464-471.

73. IVRY, R. 1993. Cerebellar involvement in the explicit representation of temporal information. Ann. N.Y. Acad. Sci. 682: 214-230.

74. Fellows, S.J., J. ERnst, M. Schwarz, et al. 2001. Precision grip deficits in cerebellar disorders in man. Clin. Neurophysiol. 112: 1793-1802.

75. Timmann, D., S. Watts \& J. Hore. 1999. Failure of cerebellar patients to time finger opening precisely causes ball high-low inaccuracy in overarm throws. J. Neurophysiol. 82: 103-114.

76. JANCKe, L., R. Loose, K. Lutz, et al. 2000. Cortical activations during paced fingertapping applying visual and auditory pacing stimuli. Cogn. Brain Res. 10: 51-66.

77. Kawashima, R., J. OKUdA, A. Umetsu, et al. 2000. Human cerebellum plays an important role in memory-timed finger movement: an fMRI study. J. Neurophysiol. 83: 1079-87.

78. Joyal, C.C., C. MeYer, G. JACQUart, et al. 1996. Effects of midline and lateral cerebellar lesions on motor coordination and spatial orientation. Brain Res. 739: 1-11.

79. Joyal, C.C., C. Strazielle \& R. Lalonde. 2001. Effects of dentate nucleus lesions on spatial and postural sensorimotor learning in rats. Behav. Brain Res. 122: 131-137.

80. IVRY, R.B., S.W. Keele \& H.C. Diener. 1988. Dissociation of the lateral and medial cerebellum in movement timing and movement execution. Exp. Brain Res. 73: 167-180.

81. Malapani, C., B. Dubois, G. Rancurel \& J. GibBon. 1998. Cerebellar dysfunctions of temporal processing in the seconds range in humans. Neuroreport 9: 3907-391.

82. BreukelaAR, J.W. \& J.C. DAlRYMPLE-Alford. 1999. Effects of lesions to the cerebellar vermis and hemispheres on timing and counting in rats. Behav. Neurosci. 113: 78-90.

83. Turner, R.S., S.T. Grafton, J.R. Votaw, et al. 1998. Motor subcircuits mediating the control of movement velocity: a PET study. J. Neurophysiol. 80: 2162-2176.

84. Schubotz, R.I., A.D. Friederici \& D.Y. von Cramon. 2000. Time perception and motor timing: a common cortical and subcortical basis revealed by fMRI. Neuroimage 11: $1-12$. 
85. Kraut, M.A., S. Marenco, B.J. Soher, et al. 1995. Comparison of functional MR and $\left(\mathrm{H}_{2} \mathrm{O}\right)-\mathrm{O}-15$ positron emission tomography in stimulation of the primary visual cortex. Am. J. Neuroradiol. 16: 2101-2107.

86. Ramsey, N.F., B.S. Kirkby, T. Vangelderen, et al. 1996. Functional mapping of human sensorimotor cortex with 3D BOLD fMRI correlates highly with $\left(\mathrm{H}_{2} \mathrm{O}\right)-\mathrm{O}-15$ PET rCBF. J. Cereb. Blood Flow Metab. 16: 755-764.

87. Joliot, M., D. Papathanassiou, E. Mellet, et al. 1999. FMRI and PET of self-paced finger movement: comparison of intersubject stereotaxic averaged data. Neuroimage 10: $430-447$

88. Mauk, M.D., J.F. Medina, W.L. Nores, et al. 2000. Cerebellar function: coordination, learning, or timing? Curr. Biol. 10: R522-525. 